\title{
Citizen science monitoring reveals a significant, ongoing decline of the Endangered Carnaby's black-cockatoo Calyptorhynchus latirostris
}

\author{
Matthew R. Williams, Colin J. Yates, William D. Stock \\ GeOFF W. BARRETT and Hugh C. FinN
}

\begin{abstract}
Citizen science monitoring programmes are making increasingly important contributions to wildlife conservation, often at spatial and temporal scales unachievable by individual or teams of researchers. They are particularly valuable in estimating population trends and management impacts, and thus informing effective conservation decisions for declining species. The quality and potential biases of citizen science data are of concern, however, and appropriate experimental design and analysis are needed to ensure that the maximum scientific value is extracted. We investigated these issues in a citizen science survey of the Endangered Carnaby's black-cockatoo Calyptorhynchus latirostris. Since 2010, citizen scientists have conducted synchronized annual counts of Carnaby's black-cockatoo at roost sites to estimate the population trend. Survey effort was substantial, with c. 150 sites surveyed by $>260$ volunteers each year. Relatively few sites were occupied, however, and only $42(16 \%)$ of the 265 sites surveyed in total accounted for $95 \%$ of all observations. Many sites were empty and survey effort was often inconsistent. Taking these issues into account, analysis showed a statistically significant decline in roost occupancy rate and a non-significant decline in the mean size of roosting flocks, with an estimated overall trend of $14 \%$ decline per annum in the number of roosting birds. We highlight three important issues for citizen science monitoring programmes: the need to maintain regular surveys of sample sites to avoid patchy data, use an appropriate model that accounts for variable survey effort, high frequency of zero counts, and sampling site turnover, and incorporate information on site characteristics to help explain variation.
\end{abstract}

Keywords Habitat loss, population decline, population monitoring, roost count, threatened species, zero-inflated

Matthew R. Williams (Corresponding author), Colin J. Yates and GeofF W. BARRETt Science and Conservation Division, Department of Parks and Wildlife, Dick Perry Drive, Kensington 6151, Western Australia

E-mail Matthew.Williams@DPaW.wa.gov.au

William D. Sтоск Centre for Ecosystem Management, Edith Cowan University, Joondalup, Western Australia

Hugh C. Finn BirdLife Australia, Peregrine House, Floreat, Western Australia

Received 16 December 2014. Revision requested 19 January 2015

Accepted 2 March 2015. First published online 1 July 2015.
To view supplementary material for this article, please visit http://dx.doi.org/10.1017/So030605315000320

\section{Introduction}

The value of citizen science projects has often been as1 cribed to their effectiveness as tools to promote community engagement and public educational outcomes (Dickinson et al., 2010; Bonney et al., 2014). Their value as scientific research has been questioned, however, with particular concerns about data quality (Crall et al., 2011; Ward, 2014) and the credibility of the results (Conrad \& Hilchey, 2011). Many citizen science projects have run for decades and it is now recognized that the generation of long-term data sets, at large spatial scales, is reliant on well-designed projects involving volunteers (Devictor et al., 2010; Hochachka et al., 2012; Tulloch et al., 2013a; Bonney et al., 2014). Cooper et al. (2014) reviewed the contribution of data generated by citizen scientists to studies of climate change impacts on birds, and found that most studies used such data extensively, although the contributions of volunteers were not always stated explicitly.

Citizen science monitoring programmes are making increasingly important contributions to wildlife conservation. Many such projects are at spatial and temporal scales unachievable by individual or teams of researchers (Dickinson et al., 2010; Bonney et al., 2014; Cooper et al., 2014) and are particularly valuable in estimating population trends and the impacts of management, thus facilitating effective conservation decisions for declining species (van Swaay et al., 2008; Tulloch et al., 2013a). The quality and potential biases of citizen science data are of concern, and appropriate experimental design (Conrad \& Hilchey, 2011), sampling protocols (Crall et al., 2011) and data analysis (Roos et al., 2012; Dennis et al., 2013) are needed to ensure that the maximum scientific value is extracted. Issues of particular concern include varying abilities of volunteers in identifying target species (Ward, 2014), variability in sampling effort between sampling sites (Dennis et al., 2013), including lack of repeated sampling at some sites resulting in patchy data sets (Bonney et al., 2014), and spatial variability in sampling, often as a consequence of the self-selection of participants and the sites surveyed (Cooper et al., 2014). There are clearly benefits to be had from citizen science 
surveys but survey designers must take care to account for methodological shortcomings that may contribute additional sources of variation to counts of birds and other wildlife (Dickinson et al., 2010).

In response to concerns about a possible decline of the Endangered Carnaby's black-cockatoo Calyptorhynchus latirostris an extensive citizen science survey, the Great Cocky Count, has been undertaken annually since 2010. Each survey involves several hundred volunteers, and in $2014>$ 290 known and putative roost sites were surveyed (Finn et al., 2014). As the only source of data on the abundance of Carnaby's black-cockatoo, these surveys provide valuable information on the population trend. We report the results from the first 5 years (2010-2014) of this community-based monitoring programme, and discuss the implications for citizen science monitoring of other threatened species.

Carnaby's black-cockatoo is a long-lived, charismatic species endemic to south-western Australia. Individual flocks once exceeded 5,000 birds (Perry, 1948; Johnstone et al., 2009) but flocks of $>500$ are now a rarity (Finn et al., 2014). As a result of land clearing for urbanization and agriculture the species has undergone substantial range contraction (Saunders, 1990), with an estimated population decline of $>50 \%$ during the past 50 years (Saunders \& Ingram, 1998; Garnett \& Crowley, 2000; Cale, 2003). Fragmentation of the remaining habitat has resulted in two geographically distinct subpopulations, with limited gene flow between them (White, 2011). The northern subpopulation is the larger of the two (DEC, 2012) and migrates annually between the breeding areas and the west coast; the southern subpopulation moves between the breeding areas and the south coast region (Saunders, 1980; Saunders et al., 2011; White et al., 2014). After migrating to coastal regions the cockatoos mass into flocks and roost communally at sites throughout the region (Shah, 2006; Berry, 2008; Berry \& Owen, 2009). Estimates of the total population size of the species vary widely $(11,000-60,000 ;$ DEC, 2012$)$ and there is no quantitative information on the size of either subpopulation. The lack of an accurate population estimate or any analysis of accumulated monitoring data has impeded understanding of the population dynamics and assessment of the long-term viability of populations of Carnaby's blackcockatoo (DEC, 2012).

To obtain reliable estimates of population size of a mobile species such as Carnaby's black-cockatoo is challenging, and the best method is to count individuals arriving at nocturnal roosts (Shah, 2006; Berry, 2008; Berry \& Owen, 2009). On the west coast the northern part of the Swan Coastal Plain bioregion (Thackway \& Cresswell, 1995) supports the largest subpopulation during the non-breeding period (Johnstone et al., 2009). This region includes the city of Perth, the state capital of Western Australia, which is expanding rapidly (WAPC, 2010). The cockatoo's predominant food sources in the region, native Banksia spp. woodlands and plantations of exotic Pinus pinaster, are subject to ongoing removal for urbanization and the management of groundwater recharge (EPA, 2007), and significant further clearing is planned for housing and extraction of raw materials (WAPC, 2010). Widespread clearing of Banksia spp. woodland has accelerated since 1950, and $61 \%$ of the original extent has been cleared (WAPC, 2010). Extensive pine plantations established since the 1920 s have progressively replaced Banksia woodlands as the major food source for the cockatoos in the region, inadvertently offsetting the loss of native habitat (Perry, 1948; Saunders, 1974; Butcher, 2007; Stock et al., 2013). However, all the remaining pine plantations in the northern part of the region are scheduled for harvesting before 2031 (Valentine \& Stock, 2008). This ongoing clearance of vegetation is likely to have a substantial negative impact on Carnaby's blackcockatoo and will further reduce the region's carrying capacity (Stock et al., 2013).

We report the results of the five annual monitoring surveys carried out during 2010-2014, with the aims of (1) determining any trends in roost utilization and flock size, (2) assessing the effectiveness of the citizen science monitoring programme, and whether any changes are needed, and (3) identifying any implications for citizen science monitoring of comparable species.

\section{Study area}

The study was conducted on the Swan Coastal Plain, which extends along the south-west coast of Australia. Perth (population 1.9 million), the fourth largest city in Australia, is located in the centre of the region (Fig. 1). The climate is Mediterranean, with cool wet winters and a prolonged summer drought. Most of the native vegetation in the region, predominantly Banksia woodlands and coastal heathland, has been cleared for urbanization, industry and agriculture.

\section{Methods}

\section{Roost counts}

Sampling sites were at known or presumed nocturnal roosting locations for Carnaby's black-cockatoo, determined from a 2006 survey and from reports from scientists and members of the public. A database of these sites is maintained by the count organizers, and newly reported sites are added each year. Individual or groups of volunteers were assigned to these sites to conduct annual, synchronized surveys (roost counts) on a set date in April (the Great Cocky Count) during 2010-2014. We examine only the 


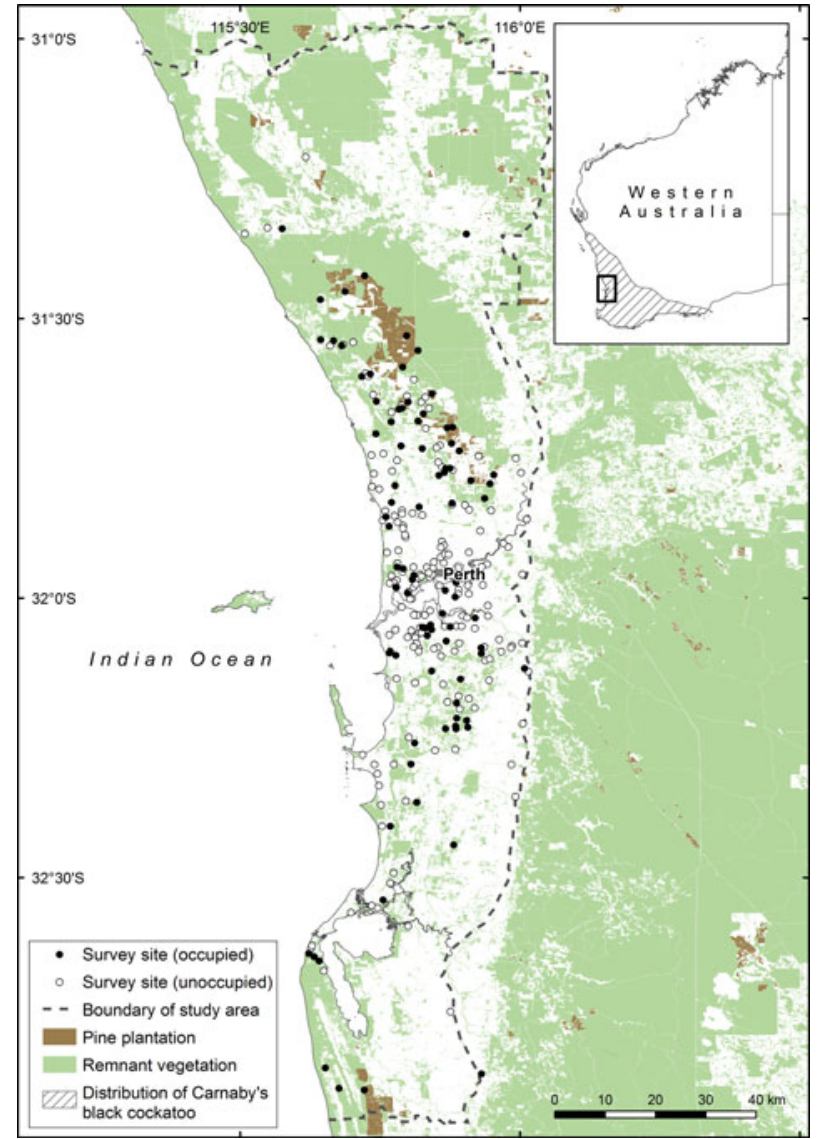

FIG. 1 The study area in south-western Australia, showing the locations of sites surveyed annually for Carnaby's black-cockatoo Calyptorhynchus latirostris during 2010-2014.

results for the northern Swan Coastal Plain region, as count data from other areas are sparse. On the coastal plain flocks consist entirely of Carnaby's black-cockatoo, whereas in forested areas to the east of the study area they may also include the superficially similar Baudin's black-cockatoo Calyptorhynchus baudinii. Although the two taxa cannot be reliably distinguished genetically (White, 2011; White et al., 2014), they are morphologically distinct, have different diets, and occupy different habitats (Saunders, 1982; Johnstone \& Kirkby, 2008). As this study was restricted to the northern Swan Coastal Plain, roosting birds consisted entirely of Carnaby's black-cockatoo (Johnstone \& Kirkby, 2008). Surveys were conducted at previously surveyed sites (resurveys) or at new sites. Count organizers prioritized resurveying of sites where birds had been recorded roosting in previous years, but volunteer turnover and other factors (e.g. destruction of roost sites) meant that it was not possible to survey all previously surveyed sites during each annual survey. Thus, the frequency of resurveys was calculated as the number of resurveys completed divided by the total number of possible resurveys.

In the days preceding each survey observers were encouraged to follow the birds to locate the roosting area precisely.
On the day of the survey, birds were tallied during a fixed time interval, from 30 minutes before until 30 minutes after sunset, as they arrived at and occupied the roost trees. Any birds that arrived but subsequently departed to roost elsewhere were excluded. Complete details of the methodology are included in the annual reports (Burnham et al., 2010; Kabat et al., 2012a,b; Finn et al., 2014). Important considerations for data analysis and interpretation of the results are that (1) the annual surveys included both known and putative roost locations, (2) new sites were added to the survey each year because count organizers actively sought to identify new roost sites (e.g. through field surveys by scientists or community reports) and because volunteers were able to nominate sites that they subsequently surveyed themselves, and (3) the sampled sites and volunteer observers, as well as the assignment of volunteers to sites, all differed from year to year.

\section{Data analysis}

As most of the birds were counted at relatively few sites (see Results), the total number recorded at each site was used to rank sites in terms of relative importance. Many roost counts yielded tallies of zero (see Results), which may be attributable to either normal variation in the number of birds roosting at a particular site (which varies from day to day as well as at broader time scales), or a design problem (e.g. the site is never used as a roosting area as it is unsuitable). Counts of the latter type are problematic because although they are irrelevant to the study they can influence estimates of mean roost size and hence any trend (Zuur et al., 2009). They also cause so-called zero-inflation or excess zeros: extra records of zeros, exceeding the number expected as part of normal variation in counts. These problems are common in citizen science surveys (Kéry \& Schmid, 2004; Schmeller et al., 2012) and appropriate statistical methods have been developed to deal with them (Cunningham \& Lindenmayer, 2005). A suitable approach, and the method employed here, is to use a zero-inflated negative binomial model that allows for the excess counts of zero and incorporates over-dispersion to account for any unknown sources of variation (Link \& Sauer, 1997; Sauer et al., 2004a; Roos et al., 2012; Tonachella et al., 2012).

This method models the data in two stages: firstly, the probability of a site being occupied each year is determined, and then for the occupied sites the mean count for each year is estimated using a log-linear model. The annual trend in both occupancy and mean roost size is also estimated. The statistical model for the occupied sites assumes that the count data follow a negative binomial distribution, the mean of which is determined by two explanatory variables: the annual trend in mean roost size, and a site effect that allows for correlation in the repeated surveys at each site. As 
the surveys sampled a significant fraction of the subpopulation of Carnaby's black-cockatoos in the region and were restricted to a few sites, the site effect was treated as fixed rather than random. The use of the negative binomial distribution (rather than the Poisson or lognormal distribution) allows for potential excess variation as a result of the many unmodelled sources of variation (overdispersion) in the roost counts (Richards, 2008). Although additional explanatory factors could be incorporated in this model, particularly relating to site characteristics, no additional information about roost site characteristics is available yet. The zeroinflated negative binomial model is comparable to those used for similar surveys, such as bird counts in North America (the Christmas Bird Count, International Shorebird Survey and Breeding Bird Survey; Sauer et al., 2004a,b; Butcher et al., 2005) and Australia (Barrett et al., 2007), annual counts of whales (the Great Whale Count; Tonachella et al., 2012), the UK Butterfly Monitoring Scheme (Dennis et al., 2013), and surveys of hedgehogs (Hogwatch; Roos et al., 2012). The details, merits and limitations of the methodology have been discussed elsewhere (Howe et al., 1989; Dobbie \& Welsh, 2001; Sauer et al., 2004a,b; Cunningham \& Lindenmayer, 2005; Fletcher et al., 2005; Humbert et al., 2009; Roos et al., 2012). This method is superior to simple linear regression models of counts or log-transformed counts because variation in the counts is modelled more realistically (Cunningham \& Lindenmayer, 2005; Richards, 2008). The generalized linear models procedure (GENMOD) of SAS/STAT v. 9.3 (SAS Institute Inc., Cary, USA) was used for model estimation.

\section{Results}

During the 5-year period 2010-2014 a total of 738 roost counts were conducted at 265 actual or purported nocturnal roost sites (Table 1). Retention of volunteers varied from year to year, with approximately one third to half of participants having undertaken surveys previously. The number of sites surveyed increased steadily each year, to a peak of 186 in 2014, with a mean of 150 (range 124-186). The number of actual roost sites (i.e. surveyed sites with a positive count) was only a small fraction $(20-30 \%)$ of the number of sites surveyed each year. The discovery rate of actual roost sites has declined steadily, with the majority $(65 \%)$ identified and surveyed in the first year of the study and only five new roosts $(6 \%)$ discovered in each of the fourth and fifth years.

At the majority of the sites $(\mathrm{n}=176,66 \%)$ no birds were recorded during any of the annual surveys. Birds were recorded at only 89 sites during the 5 -year period, and 42 of these sites account for almost all (95\%) of the records of Carnaby's black-cockatoo in the region (Supplementary Table $\mathrm{S}_{1}$ ). The relative importance of the roost sites in terms of the total number of records declined steadily: three roost sites accounted for $28 \%$ of all records and the 10 largest sites accounted for $>54 \%$ of records, the next 10 for a further $24 \%$, and the next 10 for a further $10 \%$.

The largest roosts were most likely to be resurveyed in the years after initial discovery, and the resurvey rate declined with diminishing roost size (Table 2). The 10 largest roost sites were resurveyed on 33 of 36 possible occasions after discovery but the resurvey rate declined steadily at progressively smaller and less important roost sites. The proportion of repeat surveys that recorded birds at the same roost site in subsequent years indicates the fidelity of Carnaby's blackcockatoo to roost sites. Fidelity was greatest for the 10 largest roost sites, with $91 \%$ of repeat surveys recording birds present, whereas for the 47 smallest sites, which accounted for only $5 \%$ of all records, fidelity was only $39 \%$ (Table 2 ). The 20 largest, most consistently occupied roosts $(62-91 \%$ reoccupancy rate) were resurveyed most frequently $(89-92 \%$ resurvey rate), whereas the next 20 largest sites, with moderate numbers of birds but lower repeat occupancy rates (38-58\%), were resurveyed less frequently $(69-74 \%)$, and sites with no birds had the lowest resurvey rate (50\%).

For the 89 actual roost sites, 153 of the 323 surveys (47\%) yielded counts of zero (Supplementary Tables S1 \& S2), supporting our use of a zero-inflated model in the analysis of trends. Ignoring the remaining 139 sites, which were never occupied and do not affect the estimated occupancy rates, site occupancy declined over time at a significant rate (year trend parameter $=-0.18$, Wald $\chi^{2}=4.76, \mathrm{P}=0.03$, equivalent to an annual decline in occupancy rate of $4.2-$ 4.5\%; Fig. 2). The trend in mean roost count was a decline at an annual rate of $6.8 \%$ (year trend parameter $=-0.07$, Wald $\chi^{2}=1.48, P=0.22$; Fig. 3). During 2010-2014 the estimated decline in the abundance of Carnaby's blackcockatoo, incorporating the declines in both roost site occupancy and mean roost size, was $45 \%$, or $13.8 \%$ per year. In contrast, the total counts for the region showed no trend during the period (Fig. 3).

\section{Discussion}

The survey methodology used in the Great Cocky Count presents three issues that should be considered in interpreting any estimate of a population trend for Carnaby's blackcockatoo, and may be used to inform other citizen science surveys. Firstly, not all of the known roost sites were sampled in each year of the study, and newly identified sites were added each year. As a consequence, a slightly different set of sites was surveyed each year. Secondly, in citizen science surveys where observers choose their sampling sites, or where the survey coordinators prioritize previously occupied sites, there is likely to be a bias towards allocating new observers to survey sites where cockatoos are known to 
TABLE 1 Descriptive statistics for the five annual surveys of nocturnal roost sites of Carnaby's black-cockatoo Calyptorhynchus latirostris during 2010-2014, with the date of survey, number of volunteers, volunteer fidelity, number of site surveys, number and percentage of occupied roosts, and number and percentage of newly discovered roosts.

\begin{tabular}{llllll}
\hline $\begin{array}{l}\text { Date of } \\
\text { survey }\end{array}$ & $\begin{array}{l}\text { No. of } \\
\text { volunteers }\end{array}$ & $\begin{array}{l}\text { Volunteer } \\
\text { fidelity }(\%)^{1}\end{array}$ & $\begin{array}{l}\text { No. of } \\
\text { site surveys }\end{array}$ & $\begin{array}{l}\text { No. of occupied } \\
\text { roosts (\%) }\end{array}$ & $\begin{array}{l}\text { No. of newly } \\
\text { discovered roosts (\%) }\end{array}$ \\
\hline 7 Apr. 2010 & 250 & & 157 & $35(22)$ & $58(65)$ \\
7 Apr. 2011 & $263^{2}$ & $35^{2}$ & 124 & $37(30)$ & $11(12)$ \\
15 Apr. 2012 & $294^{2}$ & $38^{2}$ & 127 & $26(20)$ & $10(11)$ \\
7 Apr. 2013 & $335^{2}$ & $47^{2}$ & 144 & $34(24)$ & $5(6)$ \\
6 Apr. 2014 & $592^{2}$ & $34^{2}$ & 186 & $38(20)$ & $5(6)$ \\
\hline
\end{tabular}

${ }^{1}$ The percentage of volunteers who had participated in a previous survey

${ }^{2}$ Includes some sites outside the study area

TABLE 2 The number of annual surveys of nocturnal roost sites of Carnaby's black-cockatoo during 2010-2014, with the percentage of birds recorded at each site group, the number of repeat surveys, the number of repeat surveys with birds present, and roost site fidelity.

\begin{tabular}{|c|c|c|c|c|c|}
\hline Site group ${ }^{1}$ & $\begin{array}{l}\text { Total no. of } \\
\text { surveys }\end{array}$ & $\begin{array}{l}\text { Birds recorded as } \\
\text { percentage of total count }\end{array}$ & $\begin{array}{l}\text { No. of repeat surveys } \\
\text { (\% of possible) }\end{array}$ & $\begin{array}{l}\text { No. of repeat surveys } \\
\text { with birds present }\end{array}$ & $\begin{array}{l}\text { Roost site } \\
\text { fidelity }^{2}(\%)\end{array}$ \\
\hline Largest 10 sites & 43 & 54 & $33(92)$ & 30 & 91 \\
\hline Next 10 sites & 42 & 24 & $32(89)$ & 20 & 62 \\
\hline Next 10 sites & 34 & 10 & $24(69)$ & 14 & 58 \\
\hline Next 10 sites & 36 & 6 & $26(74)$ & 10 & 38 \\
\hline Largest 42 sites & 160 & 95 & $118(80)$ & 74 & 63 \\
\hline Next 47 sites & 163 & 5 & $116(81)$ & 33 & 28 \\
\hline Remaining 176 sites & 415 & 0 & $248(51)$ & 0 & na \\
\hline All 265 sites & 738 & 100 & $482(62)$ & 107 & 22 \\
\hline
\end{tabular}

${ }^{1}$ Sites ranked by decreasing total counts for the period 2010-2014

${ }^{2}$ The percentage of repeat surveys of roost sites in which birds were present

roost, rather than to sites where they are absent. Although volunteers received no tangible reward for locating or surveying roost sites, it is to be expected that they would seek to conduct counts at occupied roosts, as for interested observers this is a reward in itself. In contrast, it may be expected that sites where no birds are present are less likely to be resurveyed. Similarly, the emphasis on obtaining a minimum population count of Carnaby's black-cockatoos in the study area (based on the repeated, annual survey of a large number of known roosts in the region) rather than a population estimate (based on sampling of a representative sample of sites across the region) encouraged the coordinators of the Great Cocky Count to prioritize the allocation of observers to known roosts. This bias was reflected in the results: the largest, most consistently occupied roost sites were resurveyed most frequently, whereas sites with no birds had the lowest resurvey rate.

A bias towards surveying known roosts is problematic if, for example, flocks abandon known roost sites and relocate to new or previously unoccupied sites during the next survey year. If these new or previously unoccupied sites are less likely to be surveyed, the shift in occupancy may go undetected, potentially leading to an overestimate of the rate of decline. This may not be a problem for the Great
Cocky Count, where the number of observers greatly exceeds the number of occupied sites; however, it would be prudent to rationalize the surveys by re-allocating observers from patchily surveyed, consistently unoccupied sites to strengthen the resurvey rates at other sites, in accordance with the suggestion of Tulloch et al. (2013b) to deploy observers to fill gaps in survey coverage. Examination of the spatial relationship between sites and the movement of marked birds between them would assist in determining the extent to which flocks shift to other roosts from year to year. Care should also be taken to articulate the issues that may arise when a citizen science survey does not involve sampling in the strict sense, but instead approximates a census both in its design (e.g. surveying a large proportion of occupied roosts in the region) and objectives (e.g. obtaining a minimum population count). Finally, variation between observers in their ability to count cockatoos accurately, annual variation in the observers participating in the surveys, and local and annual weather conditions pertaining during the surveys all potentially affect the detectability of birds and may therefore influence the accuracy of counts (Kavanagh \& Recher, 1983; Cunningham et al., 1999; Lindenmayer et al., 2009). These sources of variation can present problems for analysis that are common to other wildlife counts 


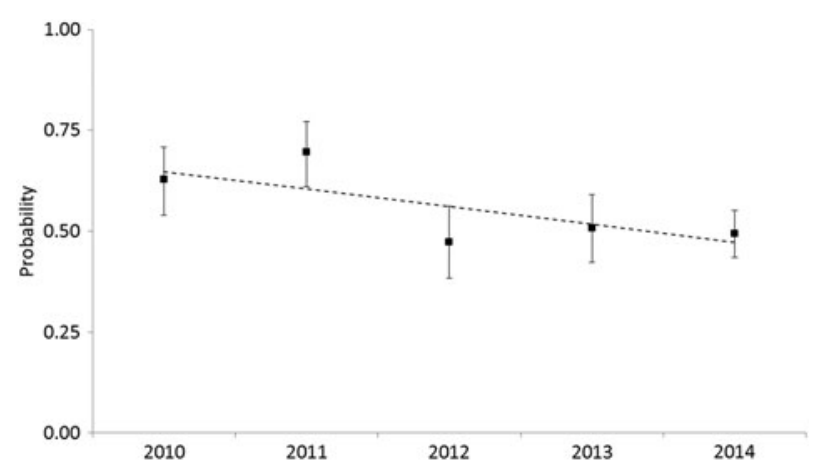

FIG. 2 Probability of occupancy of nocturnal roost sites by Carnaby's black-cockatoo in the Swan Coastal Plain region of Western Australia (Fig. 1) from annual surveys during 20102014, estimated using a logistic regression model, with 95\% confidence limits. The dashed line indicates the estimated trend.

that employ citizen scientists (Butcher et al., 2005; Roos et al., 2012; Tonachella et al., 2012), although the benefit of obtaining a large, comprehensive data set tends to compensate for this (Dickinson et al., 2010). Recent improvements in statistical methods have provided practical ways of overcoming some of the problems with point counts (Farnsworth et al., 2005), and the model used here is less susceptible to such problems. The way forward for the Great Cocky Count is to continue the repeated sampling of a (largely) fixed set of monitoring sites using the standard survey protocol, but aim to incorporate additional explanatory factors (including site and observer characteristics) into the statistical model to improve the precision of trend estimates, the accuracy of counts, and understanding of roost use.

There are three main implications of our findings for citizen science programmes. Firstly, consistent resurveys of sites should be a goal, particularly for highly mobile species such as Carnaby's black-cockatoo. To achieve this, observers should be redeployed from empty sites to ensure sampling is consistent at the most important sites. Secondly, appropriate analysis is needed, accounting for both variation in resurvey rates and the potential excess of empty sites ('zeroes'). The model used here, which accounts for the zero-inflated data of the Great Cocky Count, is one such method. Thirdly, incorporation of additional explanatory factors, such as observer effects, should be considered at the design stage. If it had been known that occupancy rates and flock sizes were to be effectively analysed separately, appropriate covariates (e.g. roost tree characteristics, availability of drinking water, distance from roads, or other site factors) could have been recorded and would have assisted in determining the reasons why some roosts are inconsistently occupied. These findings reflect those of other studies of citizen science programmes (Devictor et al., 2010; Dennis et al., 2013) but emphasize the need to account for additional sources of variation to improve the accuracy of the estimated trend (Hochachka et al., 2012).
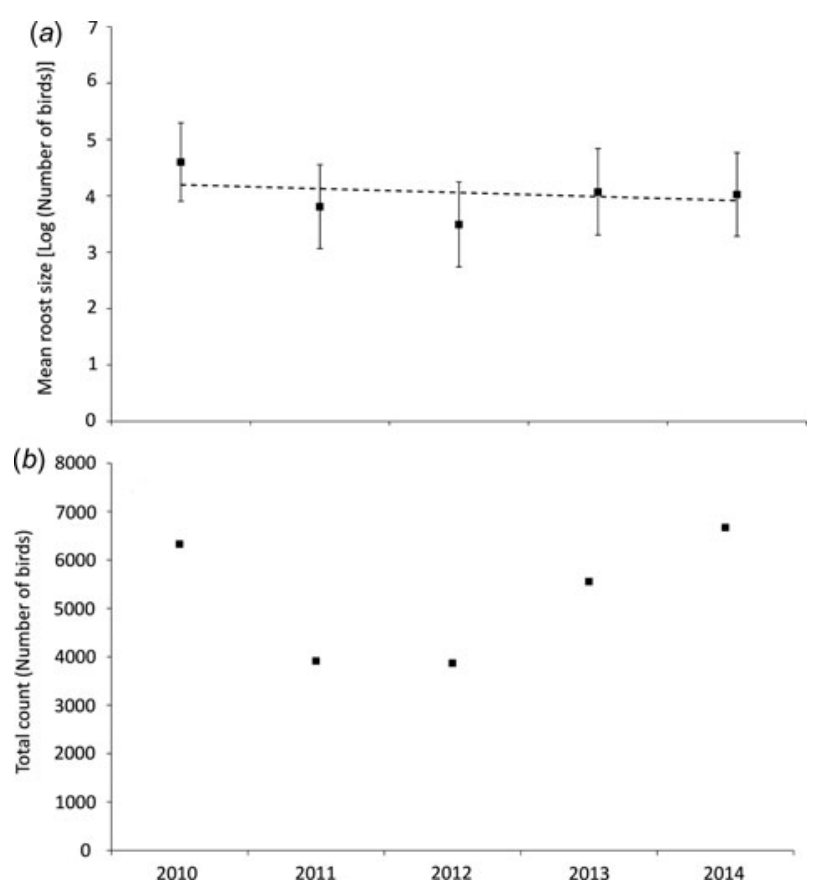

Fig. 3 (a) Mean roost size (logarithmic scale), with 95\% confidence limits, and (b) total counts of Carnaby's black-cockatoo at nocturnal roost sites in the Swan Coastal Plain region from annual surveys during 2010-2014. The mean roost size and trend (dashed line) were estimated using a log-linear zero-inflated regression model.

Programmes such as the Great Cocky Count provide opportunities for community members to contribute their observations to broader programmes investigating the ecology and population trends of prominent threatened species (Dickinson et al., 2010). Our experience with the Great Cocky Count is instructive in this regard. The growth of the Great Cocky Count has increased the replication and geographical spread of observations to provide a more complete picture of how a threatened species is responding to a landscape undergoing rapid urban development. Relating population change in a species to environmental factors is a crucial step in making monitoring data from citizen science projects relevant to management (van Swaay et al., 2008; Dennis et al., 2013; Tulloch et al., 2013a). There is clearly scope to expand the role of the Great Cocky Count survey in identifying and assessing relationships between roost counts and environmental variables, and as an ongoing data source that can be used to test these models. The need for site-specific covariates for factors that influence counting efficiency is well established for count-based surveys (Sauer et al., 2004a; Farnsworth et al., 2005) but is yet to be incorporated in the analysis of citizen sciencebased projects (Dickinson et al., 2010). A statistical framework that incorporates these covariates could provide a more realistic and accurate model of population trends in the region. Similarly, an analysis that incorporates appropriate treatment of the spatial arrangement of the sampling 
sites would be of value. The model used here can be easily extended to incorporate observer effects, habitat data or any other relevant explanatory information for individual sampling sites or at broader scales; this should be investigated to determine if a more accurate knowledge of observer variability and roost site utilization can be achieved. Maintaining a dialogue among biologists, statisticians, managers and count organizers to apply methods that accommodate the limitations of the survey and maximize the information obtained from the Great Cocky Count is important for future conservation and population monitoring of Carnaby's black-cockatoo. Our findings show that, given sufficiently large numbers of surveys and appropriate statistical analysis, even small changes in abundance (such as the annual $4 \%$ decline in roost occupancy rates) can be detected. The Great Cocky Count has two features that make it good science: the sampling protocol and effort at each site is fixed, and the resurvey rate is high $(>90 \%)$ for the most important sites. The fidelity of the cockatoos to a relatively limited number of roost sites facilitates forward planning of surveys. Any single annual survey may be subject to potentially large variation as a result of weather and seasonal variation in abundance, but this has not been a problem for other once-per-year sampling studies (O'Brien et al., 2011). The annual Great Cocky Count is supplemented with additional roost counts around the main survey date, and future analyses incorporating these data may improve estimates (e.g. Dennis et al., 2013).

The Great Cocky Count provides new data on the location and dynamics of nocturnal roosts and population trends for Carnaby's black-cockatoo on the Swan Coastal Plain. The majority of roosting birds were recorded at relatively few sites and the largest roosts were occupied more consistently across the 5 years of the survey. The characteristics of these preferred roosting sites are unknown, but factors such as isolation from disturbance and reliable access to water may be important (Saunders, 1980; Berry, 2008; Berry \& Owen, 2009). Further study is needed to assess these and any other factors that may affect use of roost sites: identifying these sources of variation will improve understanding of roost site dynamics, improve future monitoring and provide guidance on whether the suitability of sites for roosting can be improved. The large nocturnal roost sites identified should be protected from disturbance; in the past, clearing of trees has caused birds to abandon roost sites and the ultimate fate of such birds is unknown (Burnham et al., 2010).

The Great Cocky Counts provide the first systematic basis for estimating trends in the northern subpopulation of Carnaby's black-cockatoo, and several important findings have emerged. Firstly, the number of cockatoos on the Swan Coastal Plain is decreasing. In the first coordinated survey of Carnaby's black-cockatoo on the Swan Coastal Plain, undertaken in 2006 using similar techniques to the Great Cocky Count, 26 observers recorded 4,510 individuals at only 13 roost sites (Shah, 2006). In $2014>300$ observers surveyed 180 roost sites and counted 6,671 individuals at 38 occupied roosts. Despite the $>10$-fold increase in numbers of survey sites and volunteers, the total count of Carnaby's blackcockatoo in the region has remained largely unchanged. Secondly, since 2010 there has been a decline in the number of new roost sites discovered each year and this indicates that the Great Cocky Count is now sampling a large proportion of the birds that spend the non-breeding period on the Swan Coastal Plain. Thirdly, analysis of the Great Cocky Counts using an appropriate statistical model indicates there is a significant and ongoing decline in the roost occupancy rate of Carnaby's black-cockatoo on the Swan Coastal Plain, with an estimated annual decline of $14 \%$ in the number of individuals roosting in the region. This decline of a threatened species is of concern.

There are two potential explanations for the observed trend: (1) the decline at known sites may be attributable to the loss of birds from the study area, or (2) birds may have relocated from known to new roost sites, and the trend is the result of birds being displaced from existing to new sites each year. For the former, the trend analysis reported here is appropriate and provides an estimate of the losses from the region, although the true fate of such birds (mortality or emigration) is unknown. For the latter, the total counts provide a better estimate of abundance and population trend, provided that the birds at newly discovered roost sites have relocated from previously occupied roosts. A combination of both these mechanisms may be the ultimate reason for the observed decline in mean roost counts and occupancy rate. However, there are no completed studies that provide support for either scenario and it would be prudent to take a precautionary approach until better information becomes available. One thing is certain: despite increased knowledge of roost sites and improved survey focus there has been no increase in the number of occupied roosts.

Several putative causes of decline in Carnaby's blackcockatoo have been identified. The species' two major food sources, Banksia spp. woodlands and pine plantations, have been substantially reduced in extent and are increasingly fragmented. Banksia woodlands in the region have been subject to ongoing clearing for urban development and consequently are being assessed for federal listing as a threatened ecological community. Of the 24,000 ha of pine plantations present in the region in $2004,9,000$ ha $(40 \%)$ has been cleared (Gnangara Coordinating Committee, 2009; Stock et al., 2013). In addition to these major food sources the cockatoos are also known to utilize non-native food sources such as garden plants. Urban consolidation (i.e. the process of increasing housing density in an existing urban area) is also progressively reducing these food resources. Population expansion among other parrots (galahs Eolophus roseicapilla, corellas Cacatua spp. and forest 
red-tailed black-cockatoos Calyptorhynchus banksii naso) and corvids on the coastal plain has increased competition for roost sites and food sources, and results in antagonistic interactions, sometimes causing death and injury, particularly for young birds (H. Finn, pers. obs.; C. Groom, pers. comm.). There has also been increased reporting of bird deaths from vehicle strike, and mass deaths during extreme weather events, which may be associated with climate change in the region (Saunders et al., 2011). The relationship between the abundance of Carnaby's black-cockatoo and these factors requires urgent attention.

In conclusion, data from the Great Cocky Counts provide a valuable insight into roost site use and population trends in Carnaby's black-cockatoo. The results from five annual surveys indicate a substantial and ongoing decline of the population at roost sites in the northern Swan Coastal Plain region. Although the total annual counts have not shown a pronounced decline, this is probably because newly identified roost sites have been added each year, which may mask an underlying decline. If the rate of decline at roost sites is representative of the population in this region, such a rapid decline is clearly unsustainable for this long-lived, slow-breeding species. Our analyses highlight the need to employ analytical methods that account for annual variation in survey effort and appropriate treatment of zero counts. Continued surveys of the large, consistently occupied roosts are particularly important to facilitate monitoring of population trends in the region. There is a need to prioritize these roost sites to ensure that the largest, most important sites are surveyed each year, while also accounting for possible shifts to new or previously unoccupied sites.

\section{Acknowledgements}

We thank the hundreds of volunteer citizen scientists who contributed the data for this study; the staff of BirdLife Australia and the Department of Parks and Wildlife involved in coordinating Great Cocky Counts during 2010-2014, particularly Quinton Burnham, Mark Blythman, Raana Scott, Alexander Kabat and Tamara Kabat; Christine Groom for insights into the challenges of citizen science, and the solutions; Michael Craig, Sarah McEvoy, Carly Bishop, Brett Glossop and an anonymous reviewer for their comments; and Blair Pellegrino for preparing Fig. 1.

\section{References}

Barrett, G.W., Silcocks, A.F., Cunningham, R., Oliver, D.L., Weston, M.A. \& BAKer, J. (2007) Comparison of atlas data to determine the conservation status of bird species in New South Wales, with an emphasis on woodland-dependent species. Australian Zoologist, 34, 37-77.

Berry, P.F. (2008) Counts of Carnaby's cockatoo (Calyptorhynchus latirostris) and records of flock composition at an overnight roosting site in metropolitan Perth. Western Australian Naturalist, 26, 1-11.
Berry, P.F. \& OWEN, M. (2009) Additional counts and records of flock composition of Carnaby's cockatoo (Calyptorhynchus latirostris) at two overnight roosting sites in metropolitan Perth. Western Australian Naturalist, 27, 27-38.

Bonney, R., Shirk, J.L., Phillips, T.B., Wiggins, A., Ballard, H.L., Miller-Rushing, A.J. \& Parrish, J.K. (2014) Next steps for citizen science. Science, 343, 1436-1437.

Burnham, Q., Barrett, G., Blythman, M. \& Scott, R. (2010) Carnaby's Cockatoo (Calyptorhynchus latirostris) Identification of Nocturnal Roost Sites and the 2010 Great Cocky Count. Http:// birdlife.org.au/documents/CBC-gccreportaug2010.pdf [accessed 29 April 2015].

Butcher, G.S., Niven, D.K. \& Sauer, J.R. (2005) Using Christmas Bird Count data to assess population dynamics and trends of waterbirds. American Birds, 59, 23-25.

Butcher, T.B. (2007) Achievements in forest tree genetic improvement in Australia and New Zealand 7: maritime pine and Brutian pine tree improvement programs in Western Australia. Australian Forestry, 70, 141-151.

CAle, B. (2003) Carnaby's Black-Cockatoo (Calyptorhynchus latirostris) Recovery Plan. Department of Conservation and Land Management, Perth, Australia.

Conrad, C.C. \& Hilchey, K.G. (2011) A review of citizen science and community-based environmental monitoring: issues and opportunities. Environmental Monitoring and Assessment, 176, 273-291.

Cooper, C.B., Shirk, J. \& Zuckerberg, B. (2014) The invisible prevalence of citizen science in global research: migratory birds and climate change. PLOS ONE, 9(9), e106508.

Crall, A.W., Newman, G.J., Stohlgren, T.J., Holfelder, K.A., Graham, J. \& Waller, D.M. (2011) Assessing citizen science data quality: an invasive species case study. Conservation Letters, 4 , 433-442.

Cunningham, R.B. \& Lindenmayer, B.D. (2005) Modeling count data of rare species: some statistical issues. Ecology, 86, 1135-1142.

Cunningham, R.B., Lindenmayer, D.B., Nix, H.A. \& Lindenmayer, B.D. (1999) Quantifying observer heterogeneity in bird counts. Australian Journal of Ecology, 24, 270-277.

DeC (Department of Environment and Conservation) (2012) Carnaby's Cockatoo (Calyptorhynchus latirostris) Recovery Plan. Department of Environment and Conservation, Perth, Australia.

Dennis, E.B., Freeman, S.N., Brereton, T. \& Roy, D.B. (2013) Indexing butterfly abundance whilst accounting for missing counts and variability in seasonal pattern. Methods in Ecology and Evolution, 4, 637-645.

Devictor, V., Whittaker, R.J. \& Beltrame, C. (2010) Beyond scarcity: citizen science programmes as useful tools for conservation biogeography. Diversity and Distributions, 16, 354-362.

Dickinson, J.L., ZuckerberG, B. \& Bonter, D.N. (2010) Citizen science as an ecological research tool: challenges and benefits. Annual Review of Ecology, Evolution, and Systematics, 41, 149-172.

Dobbie, M.J. \& Welsh, A.H. (2001) Modelling correlated zero-inflated count data. Australian \& New Zealand Journal of Statistics, 43, 431-444.

EPA (Environmental Protection Authority) (2007) State of the Environment Report: Western Australia 2007. Department of Environment and Conservation, Perth, Australia.

Farnsworth, G.L., Nichols, J.D., Sauer, J.R., Fancy, S.G., Pollock, K.H., Shriner, S.A. \& Simons, T.R. (2005) Statistical Approaches to the Analysis of Point Count Data: A Little Extra Information Can Go a Long Way. USDA Forest Service General Technical Report PSW-GTR-191.

Finn, H., Barrett, G., Groom, C., Blythman, M. \& Williams, M. (2014) The 2014 Great Cocky Count: A Community-based Survey for 
Carnaby's Black-Cockatoos (Calyptorhynchus latirostris) and Forest Red-tailed Black-Cockatoos (Calyptorhynchus banksii naso). BirdLife Australia, Floreat, Australia.

Fletcher, D., Mackenzie, D. \& Villouta, E. (2005) Modelling skewed data with many zeros: a simple approach combining ordinary and logistic regression. Environmental and Ecological Statistics, 12, 45-54.

Garnett, S.T. \& Crowley, G.M. (2000) The Action Plan for Australian Birds 20oo. Environment Australia and Birds Australia, Canberra, Australia.

Gnangara Coordinating Committee (2009) Gnangara Sustainability Strategy: Draft for Public Comment. Http://www. water.wa.gov.au/sites/gss/Content/Projects/GSS_DraftStrategy.pdf [accessed 29 April 2015].

Hochachia, W.M., Fink, D., Hutchinson, R.A., Sheldon, D., Wong, W.-K. \& Kelling, S. (2012) Data-intensive science applied to broad-scale citizen science. Trends in Ecology \& Evolution, 27, 130-137.

Howe, M.A., Geissler, P.H. \& Harrington, B.A. (1989) Population trends of North American shorebirds based on the International Shorebird Survey. Biological Conservation, 49, 185-199.

Humbert, J.-Y., Mills, L.S., Horne, J.S. \& Dennis, B. (2009) A better way to estimate population trends. Oikos, 118, 1940-1946.

Johnstone, R.E., Johnstone, C. \& Kirkby, T. (2009) Carnaby's Cockatoo (Calyptorhynchus latirostris), Baudin's Cockatoo (Calyptorhynchus baudinii) and the Forest Red-tailed Black Cockatoo (Calyptorhynchus banksii naso) on the Swan Coastal Plain (Lancelin-Dunsborough), Western Australia. Studies on Distribution, Status, Breeding, Food, Movements and Historical Changes. Report for the Department of Planning, Western Australia.

Johnstone, R.E. \& Kirkby, T. (2008) Distribution, status, social organisation, movements and conservation of Baudin's cockatoo (Calyptorhynchus baudinii) in south-west Western Australia. Records of the Western Australian Museum, 25, 107-118.

Kabat, A.P., Scott, R., Kabat, T.J. \& Barrett, G. (2012a) 2011 Great Cocky Count: Population Estimates and Identification of Roost Sites for the Carnaby's Cockatoo (Calyptorhynchus latirostris). BirdLife Australia, Floreat, Australia.

Kabat, T.J., Barrett, G. \& Kabat, A.P. (2012b) 2012 Great Cocky Count: Identification of Roost Sites for Carnaby's Black-Cockatoo (Calyptorhynchus latirostris) and Population Count for the Swan Region. BirdLife Australia, Floreat, Australia.

KAVANAGH, R. \& RECHER, H.F. (1983) Effects of observer variability on the census of birds. Corella, 7, 93-100.

Kéry, M. \& Schmid, H. (2004) Monitoring programs need to take into account imperfect species detectability. Basic and Applied Ecology, 5, 65-73.

Lindenmayer, D.B., Wood, J.T. \& MacGregor, C. (2009) Do observer differences in bird detection affect inferences from largescale ecological studies? Emu, 109, 100-106.

LINK, W.A. \& SAUER, J.R. (1997) Estimation of population trajectories from count data. Biometrics, 53, 488-497.

O’Brien, J.M., Thorne, J.H., Rosenzweig, M.L. \& Shapiro, A.M. (2011) Once-yearly sampling for the detection of trends in biodiversity: the case of Willow Slough, California. Biological Conservation, 144, 2012-2019.

Perry, D.H. (1948) Black cockatoos and pine plantations. Western Australian Naturalist, 1, 133-135.

Richards, S.A. (2008) Dealing with overdispersed count data in applied ecology. Journal of Applied Ecology, 45, 218-227.

Roos, S., Johnston, A. \& Noble, D. (2012) UK Hedgehog Datasets and their Potential for Long-term Monitoring. BTO Research Report 598, British Trust for Ornithology, Thetford, UK.
SAUer, J.R., Link, W.A. \& Royle, J.A. (2004a) Estimating population trends with a linear model: technical comments. The Condor, 106, 435-440.

SaUer, J.R., Niven, D.K. \& Link, W.A. (2004b) Statistical analyses make the Christmas bird count relevant for conservation. American Birds, 58, 21-25.

SAUnders, D.A. (1974) The occurrence of white-tailed black cockatoo, Calyptorhyncus baudinii, in Pinus plantations in Western Australia. Australian Wildlife Research, 1, 45-54.

SAUnders, D.A. (1980) Food and movements of the short-billed form of the white-tailed black cockatoo. Australian Wildlife Research, 7 , 257-269.

SAUNDERS, D.A. (1982) The breeding behaviour and biology of the shortbilled form of the white-tailed black cockatoo Calyptorhynchus funereus. Ibis, 124, 422-455.

SAUNDERS, D.A. (1990) Problems of survival in an extensively cultivated landscape: the case of Carnaby's cockatoo Calyptorhynchus funereus latirostris. Biological Conservation, 54, 277-290.

SaUnders, D.A. \& Ingram, J.A. (1998) Factors affecting survival of breeding populations of Carnaby's cockatoo Calyptorhynchus funereus latirostris in remnants of native vegetation. In Nature Conservation: the Role of Remnants of Native Vegetation (eds D. A. Saunders, G.W. Arnold, A.A. Burbidge \& A.J. Hopkins), pp. 249258. Surrey Beatty and Sons, Chipping Norton, Australia.

Saunders, D.A., Mawson, P. \& Dawson, R. (2011) The impact of two extreme weather events and other causes of death on Carnaby's black cockatoo: a promise of things to come for a threatened species? Pacific Conservation Biology, 17, 141-148.

Schmeller, D.S., Henle, K., Loyau, A., Besnard, A. \& Henry, P.-Y. (2012) Bird-monitoring in Europe-a first overview of practices, motivations and aims. Nature Conservation, 2, 41-57.

Shaн, B. (2006) Conservation of Carnaby's Black-Cockatoo on the Swan Coastal Plain, Western Australia. Birds Australia, Perth, Australia. Http://birdlife.org.au/documents/CBC-GCC-Shah20o6Carnabys_SCP_Project_Report.pdf [accessed 1 May 2015].

Stock, W.D., Finn, H., Parker, J. \& Dods, K. (2013) Pine as fast food: foraging ecology of an endangered cockatoo in a forestry landscape. PLoS ONE, 8(4), e61145.

Thackway, R. \& Cresswell, I.D. (1995) An Interim Biogeographic Regionalisation for Australia: A Framework for Setting Priorities in the National Reserves System Cooperative Program. Reserve Systems Unit, Australian Nature Conservation Agency, Canberra, Australia.

Tonachella, N., Nastasi, A., Kaufman, G., Maldini, D. \& Rankin, R.W. (2012) Predicting trends in humpback whale (Megaptera novaeangliae) abundance using citizen science. Pacific Conservation Biology, 18, 297-309.

Tulloch, A.I.T., Possingham, H.P., Joseph, L.N., Szabo, J. \& Martin, T.G. (2013a) Realising the full potential of citizen science monitoring programs. Biological Conservation, 165, 128-138.

Tulloch, A.I.T., Mustin, K., Possingham, H.P., Szabo, J.K. \& WiLson, K.A. (2013b) To boldly go where no volunteer has gone before: predicting volunteer activity to prioritize surveys at the landscape scale. Diversity and Distributions, 19, 465-480.

Valentine, L.E. \& Stock, W. (2008) Food Resources of Carnaby's Black-Cockatoo (Calyptorhynchus latirostris) in the Gnangara Sustainability Strategy Study Area. Report to the Forest Products Commission, Western Australia.

van Swaay, C.A.M., Nowicki, P., Settele, J. \& van Strien, A.J. (2008) Butterfly monitoring in Europe: methods, applications and perspectives. Biodiversity and Conservation, 17, 3455-3469.

WAPC (Western Australia Planning Commission) (2010) Directions 2031 and Beyond: Metropolitan Planning Beyond the Horizon. Western Australian Planning Commission, Perth, Australia. 
WARD, D.F. (2014) Understanding sampling and taxonomic biases recorded by citizen scientists. Journal of Insect Conservation, 18, 753-756.

White, N.E. (2011) Molecular approaches used to infer evolutionary history, taxonomy, population structure, and illegal trade of white-tailed black-cockatoos (Calyptorhynchus spp.) in Australia. $\mathrm{PhD}$ thesis. Murdoch University, Perth, Australia.

White, N.E., Bunce, M., Mawson, P.R., Dawson, R., Saunders, D. A. \& Allentoft, M.E. (2014) Identifying conservation units after large-scale land clearing: a spatio-temporal molecular survey of endangered white-tailed black cockatoos (Calyptorhynchus spp.). Diversity and Distributions, 20, 1208-1220.

ZuUr, A.F., Ieno, E.N., W Alker, N.J., SAveliev, A.A. \& Smith, G.M (2009) Mixed Effects Models and Extensions in Ecology with R. Springer, New York, USA.

\section{Biographical sketches}

Matthew Williams, Colin Yates and Geoff Barrett are ecologists focusing on the conservation of threatened species and ecosystems in Western Australia. Matthew Williams is a biometrician and has a research interest in the ecology and conservation of Lepidoptera. Colin Yates is interested in the evolution and ecology of south Western Australia's biodiversity and its vulnerability to global environmental change. Geoff Barrett is the regional ecologist for the Swan Region, where the present study was conducted, and has a particular interest in ornithology. WILL STOCK's research has focused on the ecology and conservation of Mediterranean-type ecosystems. HUGH FINN coordinated the 2014 Great Cocky Count, and his research interest is the ecology of threatened species. 